\title{
MEC E ENTIDADES DA SOCIEDADE CIVIL: O FÓRUM NACIONAL DE EDUCAÇÃO
}

A

restrição imposta ao Fórum Nacional de Educação (FNE) quanto ao exercício de sua responsabilidade na condução, organização e coordenação da Conferência Nacional de Educação (CONAE) 2018 representa uma ruptura da ordem democrática. Tal função lhe é atribuída legalmente pelo Plano Nacional de Educação (BRASIL, 2014), no seu art. 6. ${ }^{\circ}$, parágrafo único, no qual são definidas explicitamente as responsabilidades do fórum enquanto articulador e coordenador das CONAEs, referidas no caput do mesmo artigo.

A última ação do Ministério da Educação e Cultura (MEC), no período abarcado por este Editorial, foi a Portaria do Gabinete do Ministro da Educação, n. ${ }^{\circ}$ 577, de 27 de abril de 2017 (BRASIL, 2017a), estabelecendo nova composição ao FNE que, na prática, dissolve a conformação atual. Essa portaria é antecedida pelo Decreto de 26 de abril de 2017 (BRASIL, 2017a), que reconvoca a 3. a Conferência Nacional de Educação, com a temática "A consolidação do Sistema Nacional de Educação - SNE e o Plano Nacional de Educação - PNE: monitoramento, avaliação e proposição de políticas para a garantia do direito à educação de qualidade social, pública, gratuita e laica”. Tal decreto altera datas e responsabilidades definidas, subordinando o FNE e criando enorme insegurança em relação aos entes federativos no que toca à realização de conferência democrática e com o devido apoio do poder público.

Esse decreto, assinado pela Secretária Executiva do MEC, Maria Helena Castro (o então ministro, exonerado, havia reassumido seu mandato na Câmara dos Deputados, a fim de participar de votaçóes das reformas propostas pelo governo Temer), e pelo presidente da república, ocorreu após a aprovação do documento de referência resultante do consenso proposto pelo MEC (BRASIL, 2016a) na reuniáo plenária do fórum, realizada no dia 28 de março de 2017, que contou com a participação dos titulares ou respectivos suplentes, da sociedade civil e dos representantes do MEC.

O Decreto de 9.05/2016 (BRASIL, 2016a), convocando a 3. ${ }^{\text {a CONAE, }}$ estabelece, em seu art. $1 .^{\circ}$, a

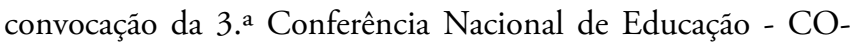
$\mathrm{NAE}$, a ser realizada na cidade de Brasília, Distrito Federal, com o tema 'A Consolidação do Sistema Nacional de Educação SNE e o Plano Nacional de Educação - PNE: monitoramento, avaliaçáo e proposição de políticas para a garantia do direito à educação de qualidade social, pública, gratuita e laica'.

Ademais, nos parágrafos $1 .^{\circ}$ e $2 .^{\circ}$, é fixada a data da realização da CONAE nacional para o primeiro semestre de 2018, em Brasília, antecedida pelas conferências em suas etapas subnacionais e conferências livres, em 2017.

DOI: 10.1590/ES0101-73302017v38n139ED 
$\mathrm{O}$ art. $2 .^{\circ}$ estabelece que a CONAE

terá como objetivo geral monitorar e avaliar o cumprimento do PNE, corpo da lei, metas e estratégias, propor políticas e açôes e indicar responsabilidades, corresponsabilidades, atribuiçóes concorrentes, complementares e colaborativas entre os entes federativos e os sistemas de educação (BRASIL, 2016a).

$\mathrm{Na}$ sequência, o art. $4 .^{\circ}$ refere-se ao desdobramento do tema central da 3. ${ }^{a}$ CONAE nos seguintes eixos temáticos:

I. O PNE na articulação do SNE: instituição, democratização, cooperação federativa, regime de colaboração, avaliação e regulação da educação;

II. Planos decenais e SNE: qualidade, avaliação e regulação das políticas educacionais;

III. Planos decenais, SNE e gestáo democrática: participação popular e controle social;

IV. Planos decenais, SNE e democratização da educação: acesso, permanência e gestão;

V. Planos decenais, SNE, educação e diversidade: democratização, direitos humanos, justiça social e inclusão;

VI. Planos decenais, SNE e políticas intersetoriais de desenvolvimento e educação: cultura, ciência, trabalho, meio ambiente, saúde, tecnologia e inovação;

VII. Planos decenais, SNE e valorização dos profissionais da educação: formação, carreira, remuneração e condições de trabalho e saúde;

VIII. Planos decenais, SNE e financiamento da educação: gestão, transparência e controle social.

O registro do lançamento da CONAE 2018, em 19 de setembro de 2016, após o impeachment, com a participação do ministro, tornou-se importante em consideraçáo aos dois pronunciamentos: o do coordenador do fórum e o do ministro da Educação. Entre outros assuntos, o coordenador do FNE ressaltou a importância de ser assegurado o orçamento para a realização das etapas municipais, regionais, estaduais e nacional da conferência, além da manutençáo do calendário previsto no decreto do mês de maio de 2016. Já o ministro da Educaçáo, Mendonça Filho, ao confirmar a realização da Conae em 2018, afirmou de forma clara:

Nós estamos dispostos a cumprir o calendário e realizar, como está posto, a Conferência Nacional de Educação dentro do ca- 
lendário estabelecido; apoiar dentro do quadro orçamentário do MEC que se realizem as conferências regionais, preparatórias para a conferência nacional; e dentro dessa pluralidade, dessa abertura para que a gente possa divergir, a gente possa também estabelecer o mínimo de convergência. Essa será a $3 .^{\mathrm{a}}$ edição da Conae ${ }^{1}$.

A solenidade pública, realizada no auditório do MEC, contou com a presença da secretária executiva do MEC, da secretária da Secretaria de Articulação com os Sistemas de Ensino (SASE), da presidente do Instituto Nacional de Estudos e Pesquisas Educacionais Anísio Teixeira (INEP), do presidente do Conselho Nacional de Educação (CNE), do coordenador do FNE e de membros de entidades da sociedade civil.

Ao compromisso assumido pelo ministro, com o decreto de 9 de maio de 2016, revogado, convocando a 3. ${ }^{\text {a }}$ Conferência Nacional de Educaçáo, impunha-se a necessidade de medidas urgentes em relação à organização da CONAE, por meio da elaboração de documentos nacionais visando à sua operacionalização articulada com os fóruns estaduais e municipais.

Iniciou-se, então, a formulação do Documento de Referência da Conae 2018 por um grupo de pesquisadores voluntários do campo da educação, compromissados com as decisões do pleno do fórum relativas a tema, formato, objetivos geral/específicos, bem como aos eixos. Ao contrário das conferências anteriores, os responsáveis pela elaboração de tal documento, dessa vez, não contaram com nenhum apoio técnico ou administrativo do MEC, tendo de atuar como voluntários. No início de 2017 a primeira versão do documento foi apresentada, via internet, às entidades para conhecimento e análise, com o objetivo de formar um consenso, conforme as exigências do regimento interno da CONAE.

A primeira reuniáo, convocada pelo coordenador do FNE, realizou-se em Brasília, nos dias 20 e 21 de fevereiro de 2017. Reuniram-se as duas comissóes do fórum:

1. Sistematização, Monitoramento e Avaliação, coordenada pela SASE, do Ministério da Educação, e pela Associação Nacional de Pós-Graduação e Pesquisa em Educação (ANPED);

2. Articulação, Mobilização e Infraestrutura, com a coordenação da Central Única dos Trabalhadores (CUT) e Secretaria de Educaçáo Básica (SEB) do MEC.

Mesmo com a não sensibilização do MEC para prover apoio necessário para os integrantes titulares ou suplentes das comissōes, o descompromisso do MEC não impediu o deslocamento dos representantes das entidades do fórum, que se reuniram nesse dia, em espaço do ministério, mesmo com a presença dos representantes do MEC, tornando-se a reuniáo oficial. 
No dia 20 de fevereiro de 2017 (BRASIL, 2017a), como previsto, a primeira versão do Documento de Referência foi apreciada, analisada e debatida em reuniáo da comissáo do FNE com a participaçáo de entidades da sociedade civil e representantes do MEC visando ao encaminhamento do documento, já qualificado, para a reuniáo do pleno, planejada para o dia 21 de fevereiro de 2017. O Documento Referência recebeu, por parte do secretário executivo adjunto Felipe Sartori Sigollo, diversos destaques, que poderiam ser de supressão completa de alguns itens como, por exemplo, a apresentação, bem como a supressão completa, parcial ou substituição de alguns dos oito eixos, explicitados pelo decreto de maio de 2016, ou sua reduçáo para quatro outros novos eixos, como proposto. Todo esse movimento de supressões ou alteraçóes foi feito sem proposta de emendas nem/ou justificativas. Ao contrário disso, as entidades que apresentaram destaques ao Documento de Referência - Centro de Estudos Educação e Sociedade (CEDES), Movimento Interfóruns da Educação Infantil do Brasil (Mieib) e Lésbicas, gays, bissexuais, transgêneros e intersexuais (LGBTI) — o fizeram acompanhados de emendas aditivas e de suas respectivas justificativas.

Partindo da análise do Documento de Referência da CONAE, o CEDES considerou que o texto apresentava forte conotação de privilégio das diversidades em detrimento das características da sociedade brasileira, como, por exemplo, a má distribuiçáo de bens e a procura pela igualdade como base da justiça social. Apresentou várias emendas ao documento, ressaltadas aqui as mais importantes, que propunham incluir no texto as dimensóes sociais, econômicas e políticas, bem como a concepção de desigualdade que marca profundamente a sociedade brasileira.

A decisão da Comissão de Sistematização, orientada pela votação dos seus componentes, embora com abstenção de vários representantes do MEC, foi a de encaminhar o Documento de Referência para a reunião plenária do fórum, incluindo todas as emendas apresentadas, com suas respectivas justificativas. Aos representantes do MEC foi solicitado que exibissem na reunião plenária em questão todas as proposiçóes em forma de emendas substitutivas e justificativas, tendo em vista a busca de articulação e de consenso visada pelo fórum. Esse espaço transformou-se em cenário de luta, com manifestaçóes de interesses divergentes e situaçōes de confrontos, enfrentamentos e tensōes que refletiam a disputa entre concepçóes diferentes de Estado, sociedade e educação. Ao mesmo tempo, o MEC manifestou explicitamente seu estranhamento ao fórum, relativas às atribuições que ele, o MEC, the cobrou, sobre seu espaço no governo, seu papel e sua legitimidade, o que não era novidade. Representantes da SASE e Secretaria Executiva (SE) sempre afirmavam que, no novo contexto político, o MEC estava avaliando o espaço do fórum nessa instância de governo. Sua exclusão como interlocutor do MEC sobre as políticas públicas e programas do "novo governo" era evidente.

Porém, contraditoriamente, na reunião do pleno do fórum, realizada no dia 21 de fevereiro de 2017, cuja agenda previa a votação do Documento de Referência, surgiram novos posicionamentos do MEC. No espaço dos encaminha- 
mentos, tanto a secretária da SASE, Regina de Assis, identificando-se como representante do ministro e afirmando seu compromisso com a realizaçáo da CONAE 2018, conforme sua manifestação em setembro de 2016, quanto Carlos Lenuzza, da Coordenação de Aperfeiçoamento de Pessoal de Nível Superior (CAPES), apresentaram a proposta de construçáo de um Documento de Referência consensual pelas partes envolvidas: MEC e representantes da Comissão de Sistematização. Analisada e debatida pelo pleno do fórum, a proposição de consenso foi votada e aprovada com os seguintes encaminhamentos:

1. A partir do dia 22 de fevereiro de 2017 , às $10 \mathrm{~h}$, seria iniciada, na CAPES, uma série de reuniôes dos representantes do MEC e da Comissão de Sistematização, tendo em vista os estudos e as negociaçóes para a elaboração de um novo Documento Referência consensuado;

2. O referido documento, resultante da negociação, deveria ser enviado com antecedência de uma semana para todas as entidades do fórum com o fim de garantir a reunião das comissóes especiais e do pleno nos dias 27 e 28 de março, respectivamente;

3. O MEC deveria assumir compromisso de realização da reuniáo com apoio financeiro para os deslocamentos para Brasília;

4. Foi acertado que o MEC receberia, após a aprovação do documento, a Comissão de Articulação, Mobilização e Infraestrutura do FNE para discutir aspectos operacionais e financeiros da CONAE 2018 para as decisôes financeiras necessárias para sua realização.

O compromisso com o calendário da realização da CONAE 2018, em suas diferentes etapas - municipais, estaduais e nacionais e as conferências livres foi mantido, conforme previsto no decreto de maio de $2016^{2}$.

As reunióes previstas ocorreram com a articulação das coordenaçóes da Comissão de Sistematização do fórum, com a representação da presidente da ANPEd, e a coordenação do MEC ficou sob a responsabilidade do representante da CAPES. Os demais representantes de entidades da sociedade civil pelo fórum foram: Fórum de Professores da Federação de Sindicatos de Professores e Professoras de Instituiçōes Federais de Ensino Superior e de Ensino Básico Técnico e Tecnológico (PROIFES); Confederação Nacional dos Trabalhadores em Educação (CNTE); Fóruns de Educação de Jovens e Adultos (EJA) do Brasil; e Campanha Nacional pelo Direito à Educação. A representação do MEC foi a SASE; a Secretaria de Educação Superior (SESu); a Secretaria de Educação Básica (SEBE); e a Secretaria de Educação Continuada, Alfabetização e Diversidade e Inclusão (SECADI). Também esteve presente, entre outros representantes, o coordenador do Documento de Referência, Luiz Dourado. À mesa estavam questóes relacionadas 
à gestão democrática, ao financiamento da educação (Emenda Constitucional n. ${ }^{\circ}$ 95), ao direito ao ensino superior e à reforma do ensino médio. Com muito esforço e empenho, o documento pôde ser finalmente consensuado e encaminhado ao fórum por e-mail, com as assinaturas de Carlos Lenuzza, pelo MEC, e de Andrea Barbosa, pela Comissão de Sistematização.

As reuniōes da Comissão de Sistematização, Monitoramento e Avaliação e do Pleno do Fórum ocorreram na data prevista. No início da reuniấo da comissão , iniciada com a apresentação do Documento Consensuado (FÓRUM NACIONAL DA EDUCAÇÃO, 2017b), o secretário executivo adjunto Felipe Sartori Sigollo apresentou novos destaques de supressão ao Documento de Referência Consensuado com o MEC em claro processo de dissenso interno. Ou seja, enquanto as entidades da sociedade civil suspenderam seus destaques conservando o compromisso do apoio ao documento, resultante do trabalho de efetivação do consenso, o secretário adjunto, de forma isolada, não o aceitou. Confirmava-se assim, mais uma vez, as divergências que efetivamente marcam concepçōes diferentes de Estado, sociedade e educação.

Novos destaques recebidos pelo Documento de Referência Consensuado³:

- mudanças do calendário da CONAE de abril de 2018;

- Supressão dos itens:

- 20, que supóe a "forte mobilização nacional para o efetivo cumprimento das metas instituídas pelo Plano Nacional de Educação (PNE), com a destinação dos $10 \%$ do [produto interno bruto] PIB para a educação, com o aporte de recursos do fundo social do pré-sal e dos royalties do petróleo e, ainda, pela ampliação dos percentuais constitucionais mínimos obrigatórios para a educação, conquistas dos movimentos sociais e das entidades educacionais, bem como a previsão de novas fontes e recursos...";

- 32, ou seja, "tema central das últimas conferências, o Sistema Nacional de Educação (SNE) ganhou impulso no último período. Aspiração defendida por décadas e inscrito na Constituição Federal no ano de 2009 (por meio da Emenda Constitucional 59/2009), o SNE é definido pelas últimas conferências como "expressão institucional do esforço organizado, autônomo e permanente do Estado e da sociedade, compreendendo os sistemas de ensino da União, dos estados, do Distrito Federal e dos municípios, bem como outras instituiçóes públicas ou privadas de educação";

- 37, que trazia que a Constituiçáo e a [Lei de Diretrizes e Bases] LDB definem que a educação escolar, "inspirada nos princípios de liberdade e nos ideais de solidariedade humana, tem por finalidade o pleno desenvolvimento do educando, seu preparo para o exercício da cidadania e sua qualificação para o trabalho" e que o "ensino será ministrado com base nos seguintes princípios: a) [...] liberdade de aprender, ensinar, 
pesquisar e divulgar a cultura, o pensamento, a arte e o saber; b) pluralismo de ideias e de concepçóes pedagógicas; c) respeito à liberdade e apreço à tolerância; d) gestão democrática do ensino público; e) garantia de padrão de qualidade", entre outros;

- 87, isto é, "os valores transferidos pela União para a execução das açóes supletivas de caráter financeiro e técnico não poderão ser considerados pelos beneficiários para fins de cumprimento do disposto no art. 212 da Constituição Federal. As receitas e despesas com manutenção e desenvolvimento do ensino serão apuradas e publicadas nos balanços do Poder Público e nos relatórios a que se refere o $\$ 3 .^{\circ}$ do art. 165 da Constituição Federal. Visando garantir planos decenais consequentes define-se que, até o final do primeiro semestre do oitavo ano de vigência do PNE, o Poder Executivo encaminhará ao Congresso Nacional, sem prejuízo das prerrogativas desse poder, o projeto de lei referente ao PNE a vigorar no período subsequente, que incluirá diagnóstico, diretrizes, metas e estratégias para o próximo decênio";

- 92, com a supressão da expressão SUPERIOR do texto: "A concepção político-pedagógica para o alcance dessa educaçáo passa pela garantia de princípios como: o direito à educação básica [...]. Garantir o direito à educação, portanto, só se efetiva quando é assegurada a qualidade nessa perspectiva";

- 134, com: "A gestão democrática e a participação popular precisam ser vivenciados em todas as esferas e por todos os sujeitos do campo educacional. Por isso torna-se indispensável a participação no planejamento, execução e avaliação dos projetos e atividades educativas tanto na educação básica como na educação superior. Bem como a existência efetiva do Fórum Nacional de Educação e dos fóruns estaduais, municipais e distrital da educação, a materialização do regime de colaboração entre os sistemas de ensino e a regulamentaçáo da cooperaçáo federativa entre os entes, o fortalecimento da autonomia e o controle social";

- 193, com: "Os movimentos sociais, na sua pedagogia, nos ensinam que a diversidade, os direitos humanos, a justiça social e a inclusão e suas múltiplas dimensóes são e devem ser consideradas como parte integrante, estrutural e estruturante da vida política, histórica, social, econômica, cultural e educacional";

- 265, com: "Essas políticas de formação e gestão dificultam o cumprimento do PNE no que tange à elevação do salário do magistério a patamares equivalentes ao de outras categorias profissionais - de outras áreas -, que apresentam o mesmo nível de escolaridade e o direito ao aperfeiçoamento profissional contínuo por meio de programas de formação continuada de curta e longa duraçáo, incluindo cursos lato e stricto sensu, 
materializados na Meta 17 da Lei 13.005 de 2014, que instituiu o Plano Nacional de Educação";

- 266, com: "Mudança significativa vem sendo proposta por inúmeras leis e proposiçóes, Escola sem Partido ou lei da mordaça em tramitação em câmaras estaduais e no Congresso Nacional, quanto ao caráter do trabalho dos profissionais da educação, com a instituiçâoo de mais controle, sobretudo em relação às atividades do magistério, em iniciativas que visam coibir a liberdade de ensino e de formação crítica, científica e humanista da infância e da juventude. $\mathrm{Na}$ contramão às concepçóes autoritárias e reducionistas, não há neutralidade no ato pedagógico, uma vez que a própria educação é um ato político, não partidário, portanto, imbuído de intencionalidade, que visa ampliar, aprofundar e garantir direitos na formação para a cidadania, com reconhecimento das diferenças e no combate das desigualdades com justiça social. Neste sentido, reafirma-se a necessidade de garantir formaçáo ético-política- estética, que possibilite ao educando e à educanda, enquanto ser histórico, o conhecimento pleno da realidade e de seus condicionantes, proporcionando uma leitura crítica do mundo e sua auto percepção como sujeito constitutivo de identidade e com possibilidades concretas de intervir neste mundo em busca de igualdade e justiça social";

281, com: "Somente com o cumprimento desses dispositivos podem-se alterar as péssimas condiçôes de trabalho e de saúde a que é submetida grande parte dos profissionais da educação, superando o quadro atual, marcado por inúmeros processos de adoecimento, a exemplo da síndrome de Bournout, tema tratado de forma recorrente na literatura concernente. De fato, ao lado de baixos salários, a intensidade do trabalho na atividade profissional causa mais adoecimento";

- 294, com: "O advento da emenda constitucional 95 poderá implicar a redução dos investimentos em educação, portanto, uma grande mobilização da sociedade e, especialmente, dos setores e dos segmentos educacionais, deve se efetivar não só para evitar tal redução como para viabilizar a efetivação de novas fontes, que se acoplem àquelas já existentes, para que as metas do PNE (2014-2024) sejam alcançadas";

- 295, com: "Além disso, há que se mobilizar também os governos dos entes federados, instâncias legislativas federais, estaduais distrital e municipais, e movimentos sociais organizados nos diversos setores da sociedade, visando eliminar obstáculos para a construçáo de pactos e consensos entre os diversos setores do campo social, que redundem em melhorias nas políticas públicas. Esse é o cenário mais amplo, que emoldura e desafia os participantes da CONAE em sua capacidade de formulação e incidência nas políticas públicas”;

- 319, com: "Deverá ser garantido o financiamento das metas do PNE (2014-2024), bem como a ampliação dos recursos para atingir os 10\% 
do PIB no volume de recursos aplicados à educação, até 2024, o que requer ampla discussão e mobilizaçáo para que a aprovação da Emenda Constitucional No. 95, de 2016, que instituiu o 'Novo Regime Fiscal no Âmbito dos Orçamentos Fiscal e da Seguridade Social da União, que vigorará por vinte exercícios financeiros' (BRASIL CF, 1988, Art. 106), não afete a educação. Esse Novo Regime Fiscal possui como fundamento efetivar um profundo e intenso ajuste sobre as despesas correntes da União, exigindo a reunião de esforços em busca da garantia dos volumes orçamentários/financeiros aplicados em educação, até 2024".

Tais destaques, muitas das vezes restritivos aos direitos à educação e, frequentemente, oriundos do texto do PNE, demonstrando resistência a sua implantação, apontam divergências tão fundamentais da SE tornando inviável a concretizaçáo do consenso: mudança do calendário da CONAE; outra concepção sobre o Sistema Nacional de Educação; retrocessos da igualdade de gênero, exclusôes das proposiçóes de financiamento e marcadamente o Custo Aluno-Qualidade (CAQ) e o Custo Aluno-Qualidade Inicial (CAQi), das concepçôes sobre gestão democrática e garantia do ensino superior como direito à educação, o que impediria a privatização do ensino superior público.

O Documento de Referência foi enviado para o pleno do fórum no dia 28 de março de 1917. Encaminhando o processo de votação, o representante da CAPES pelo MEC expôs, inicialmente, a proposta de manifestaçóes de quatro defesas e quatro contrárias aos destaques do MEC. Recusada essa proposta por parte da maioria do plenário, o proponente mudou sua proposição para votação e ele faria uma Declaração de Voto do MEC de caráter coletivo.

Em sua Declaração de Voto, entre outros aspectos, explicitou que estavam em jogo pelo fórum o poder e a captura da hegemonia do MEC, salientando que considerava o "FNE agindo em disputa de um terceiro poder, usurpando assim o poder do Estado" 4 .

\section{O resultado da votação foi de 23 a 9 votos.}

As mencionadas divergências evidenciam a concepção do Estado, da sociedade e da educação vigente no pós-liberalismo conservador, no qual se ancora o governo Temer, com o apoio explícito de entidades empresariais e financeiras, o que se repete também na educação. Os aliados da sociedade civil que referendam as formulações de políticas do MEC incluem empresários do setor privado da educação e do capital financeiro.

Conforme acordado, a coordenação do fórum encaminhou à SE os nomes dos membros da Comissão do FNE que tratariam das questóes do financiamento da CONAE 2018, sendo indicadas duas alternativas para a realização da reunião. No entanto, essa reunião foi suspensa às vésperas de sua realização, sem justificativas consistentes. 
A resposta do MEC oficialmente foi o novo decreto publicado no Diário Oficial (DO) de 26 de abril de 2017, convocando a 3. ${ }^{a}$ Conferência Nacional de Educação, pelo presidente da república "no uso de suas atribuiçóes que lhe conferem o art. 84, caput, incisos IV e VI, alínea "a", da Constituição". Esse decreto revoga, em seu art. 10, o decreto de 9 de maio de 2016, assinado pela entấo presidente Dilma Rousseff.

Articulou-se com a nova Portaria do MEC, n. ${ }^{\circ} 577$, publicada no DO de 27 de abril de 2017, que dispóe sobre o FNE, mudando sua composição, tanto em relação às entidades participantes quanto ao número de entidades que o compunha. A Portaria n. ${ }^{\circ} 577$ revoga, expressamente, em seu art. $7 . .^{\circ}$ as portarias n. ${ }^{\circ} 1.407$, n..$^{\circ} 502$ e n. ${ }^{\circ} 1.033$.

Em nota publicada em 7 de maio de 2017 pelo MEC, este iniciou seu posicionamento sobre o decreto e sobre a portaria, recém-publicados, com a afirmação de que "corrigiu distorçôes claras em medidas adotadas pela gestão Dilma, tanto na realização da CONAE 2018 quanto na composição do Fórum Nacional de Educação (FNE), que estava sendo usado como propósito político-partidário".

Ambos os documentos foram analisados em reunião do fórum do dia 17 de maio em Belo Horizonte, em dois documentos de trabalho. No primeiro foram comparados o decreto de 9 de maio de 2016 com o decreto de 27 de abril de 2017. No segundo documento foram analisadas a Portaria MEC n. 577 e as Portarias MEC n. ${ }^{\circ}$ 1.407, de 14 de dezembro de 2010; n. ${ }^{\circ}$ 502, de 9 de maio de 2012; e n. ${ }^{\circ} 1.033$, de 9 de dezembro de 2014.

O estudo comparativo permitiu as seguintes conclusões sobre as análises referentes:

- DECRETO: "Desrespeita as deliberaçóes do Pleno do FNE com relação ao cronograma da CONAE 2018; subordina o FNE ao MEC na condução da CONAE 2018, ao transferir ao MEC a elaboração das diretrizes gerais e organizativas do FNE, contrariando o artigo 6. ${ }^{\circ}$ da Lei n. 13.005/2014. Sem critérios, prorroga os tempos para a realização das etapas municipais, estaduais e distrital da CONAE 2018, promovendo conflitos e deixando indefinida a etapa nacional da conferência. Além disso, continua a desconsiderar a necessidade de definiçóes em relação aos sistemas de monitoria e sistematização das emendas ao documento referência, deixando um vácuo na elaboração do documento base, o que consequentemente desorganiza toda a metodologia que construímos desde a Conferência Nacional de Educação Básica dos anos de 2007 e 2008 (CONEB 2007/2008). Ademais, a ausência da definição, por parte do MEC, do financiamento para CONAE 2018 inviabiliza sua realização. O decreto, ainda, suprime a redação mais abrangente relativa ao objetivo geral da CONAE 2018; restringe as contribuiçôes da Conae para a elaboração da política nacional e na indicação de açôes que promovam avanços nas políticas públicas e; desconsidera a atribuiçáo do FNE de fazer o monitoramento do PNE, condiçóes que estavam no Decreto do Executivo de 09 de maio de 2016, revogado pelo Decreto em análise" (BRASIL, 2017d). 
- PORTARIA do MEC n. $^{2} 577$ "desmonta a estrutura atual do FNE (Fórum Nacional de Educação) e, para a nova composição, não menciona expressamente as finalidades e competências do Fórum. Amplia a representação governamental e empresarial, reduz a participação da representação da Sociedade Civil, excluindo de forma direta a CONTEE (Confederaçáo Nacional dos Trabalhadores em Estabelecimentos de Ensino), FASUBRA (Federação de Sindicatos dos Trabalhadores em Universidades Brasileiras), PROIFES (Federação de Sindicatos de Professores e Professoras de Instituiçóes Federais de Ensino Superior e de Ensino Básico Técnico e Tecnológico), ANPED (Associação Nacional de Pós-Graduação e Pesquisa em Educação), CEDES (Centro de Estudos Educação e Sociedade), CNC (Confederação Nacional do Comércio), ABMS (Associação Brasileira de Mantenedoras de Ensino Superior), FORUNDIR (Fórum Nacional de Diretores de Faculdades) e, de forma indireta, pois a portaria afirma que será o Ministro o responsável para escolher qual entidade terá assento no FNE: a ABGLT (Associação Brasileira de Lésbicas, Gays, Bissexuais, Travestis e Transexuais), UBM (União Brasileira de Mulheres), CADARA (Comissão Técnica Nacional de Diversidade para Assuntos Relacionados à Educação dos Afro-brasileiros), CEERT (Centro de Estudos das Relaçóes de Trabalho e Desigualdades), CNEEI (Comissão Nacional de Educação Escolar Indígena), Campanha (Nacional pelo Direito à Educação), TPE (Todos pela Educação), Fóruns EJA (Educação de Jovens e Adultos), MIEIB (Movimento Interfóruns da Educação Infantil do Brasil), ANPAE (Associação Nacional de Política e Administração da Educação), ANFOPE (Associação Nacional pela Formação dos Profissionais da Educação), CUT (Central Única dos Trabalhadores), UGT (União Geral dos Trabalhadores), CONTAG (Confederação Nacional dos Trabalhadores na Agricultura) e MST (Movimento dos Trabalhadores Rurais Sem-Terra). A Portaria afirma que a nova composição do FNE será formada pelo Ministro, ao autorizá-lo a indicar pessoas de reputaçáo ilibada e comprovada atuação nas áreas de educação, cultura, ciência, tecnologia e pesquisa, tirando assim o caráter do FNE, como amplo espaço de debate sobre as políticas educacionais, equiparando ao caráter do CNE que é composto por indicaçáo política. $\mathrm{O}$ art. 2..$^{\circ}$ da Portaria ataca a atual estrutura do FNE, seus procedimentos operacionais e ameaça a coordenaçáo do FNE, que está a cargo da Sociedade Civil, com mandato até dezembro de 2018. Fere o artigo 6. ${ }^{\circ}$ da Lei n. ${ }^{\circ}$ 13.005/2014, ao retirar do FNE o papel de coordenar as Conferências de Educação e delegar esta atribuição à Secretaria Executiva do MEC, reafirmando o artigo 8. ${ }^{\circ}$ do Decreto do Executivo de 26 de Abril de 2017" (BRASIL, 2017d).

A Carta Aberta ao ministro da Educação termina com encaminhamento de providência:

[Elencados] [...] os considerandos exigimos da Presidência da República e do Ministério da Educação, de forma imediata, a revo- 
gação de Decreto do Executivo de 26 de Abril de 2017, mantendo em vigor o Decreto do Executivo de 09 de Maio de 2016, bem como a revogação da Portaria do MEC n. ${ }^{\circ} 577$, de 27 de Abril de 2017, mantendo em vigor as Portarias do MEC n. ${ }^{\circ} 1.407$, de 14 de dezembro de 2010, n. ${ }^{\circ}$ 502, de 09 de maio de 2012, e n. ${ }^{\circ}$ 1.033, de 09 de dezembro de 2014 (BRASIL, 2017d).

Concomitantemente às avaliaçóes e articulaçóes das entidades do campo educacional, iniciativas da aposição ao governo Temer foram adotadas no sentido de solicitar esclarecimentos, requerer audiências públicas e sustar os efeitos dos atos unilaterais editados pelo governo em relação ao FNE e às conferências.

$\mathrm{Na}$ mesma reuniāo foi decidido que as medidas e recomendaçóes exaradas pelo Ministério Público Federal (MPF) referentes tanto ao decreto quanto à recomendaçáo de revogaçáo da portaria, bem como os ofícios protocolados por deputados e senadores no Congresso Nacional, serão acompanhadas atentamente pelos membros dos fóruns nacional, estaduais e municipais.

A recomendação do MPF da revogação da Portaria n. ${ }^{\circ} 577$ do MEC concretizou-se por meio da Procuradoria Federal dos Direitos do Cidadáo (PFDC), que a encaminhou no dia 10 de maio ao presidente da república, Michel Temer, e ao ministro da Educação, Mendonça Filho.

Para a PFDC (BRASIL, 2017), conforme seu documento, a medida desrespeita as cláusulas da Constituição Federal acerca da participação e da independência, além de violar os princípios constitucionais da gestão participativa e democrática e de contrariar a literalidade do art. 6. ${ }^{\circ}$ da Lei n. ${ }^{\circ} 13.005 / 2014$ do PNE, que pauta a atuação do FNE.

Todo esse movimento de recrudescimento das violaçóes do direito humano à educação no Brasil tem preocupado a comunidade internacional nas esferas diplomáticas e dos organismos internacionais.

O enfraquecimento das instâncias democráticas de participação, principalmente o desmantelamento do Fórum Nacional de Educação com a portaria de Mendonça Filho, assim como os retrocessos da igualdade de gênero, do financiamento da educação pública e da não implementação da Lei do Plano Nacional de Educação 13.005/2014, foi levado às esferas internacionais pela Campanha Nacional pelo Direito à Educação nas principais instâncias de direitos humanos da Organização das Naçóes Unidas (ONU) no contexto da Revisão Periódica Universal do Brasil em abril e maio de 2017.

Diplomatas de todos os continentes tiveram acesso ao momento de retrocesso que o Brasil vive e esse movimento de denúncia quase em tempo real $e$ in loco na Suíça em várias reunióes em missóes permanentes de países e em momentos oficiais da ONU por meio da Campanha Nacional pelo Direito à Educação, rede composta de mais de 200 organizaçóes e movimentos em todo o 
Brasil, o que surtiu grande efeito e gerou um enorme constrangimento para o Ministério da Educação de Michel Temer. O Brasil foi questionado pela não implementação do PNE.

Após as denúncias, como resultado, em Genebra, na ONU, nesse processo de sabatina diplomática que é a Revisão Periódica Universal, com a participaçáo de 103 países, 45 deles, ou seja, $43,7 \%$, consideraram as recomendaçóes e denúncias presentes no relatório da campanha, que foi contemplado no relatório oficial da sociedade civil compilado pela ONU (CAMPANHA NACIONAL PELO DIREITO À EDUCAÇÃO, 2017).

As entidades devem iniciar o debate sobre a Conferência Nacional Popular de Educação (CONAPE), que será realizada pelo movimento social e por entidades do campo da educação, sem a participação do MEC.

Estão previstos atos em 6 e 7 de junho no Congresso Nacional em defesa do PNE, da Conferência Democrática, culminando com o protesto contra o desmonte do FNE, ação das entidades da sociedade civil que o compuseram ou ainda o compóem, e encaminhamentos relativos à CONAPE 2018.

\section{Editores da Revista Educaçâo \& Sociedade}

\section{Notas}

1. Apontamentos da reuniáo de 20 e 21 de fevereiro de 2017.

2. Apontamentos da reunião de 27 de fevereiro de 2017.

3. Emendas ao documento consensuado/apontamentos da reuniáo de 27 de fevereiro de 2017: estudo resultante dos respectivos destaques apresentados confrontados com Documento de Referência consensuado (circulação interna no FNE). Tal documento consensuado foi aprovado no dia 28 de maio de 2017, em reuniáo do FNE.

4. Apontamentos de reunião em Brasília em 28 de fevereiro de 2017.

\section{Referências}

BRASIL. Fórum Nacional de Educação. Carta Aberta ao Ministério da Educação. Belo Horizonte, 17 maio 2017a.

Fórum Nacional de Educação. Conae, 2016a. Disponível em: <http://fne.mec. gov.br/documentos/conae-2018>. Acesso em: 17 maio 2017.

Lei n. ${ }^{\circ} 13.005$, de 25 de junho de 2014. Plano Nacional de Educação. Diário Oficial da União, Seção 1 (Ed. Extra), 26 jun. 2014. p. 1-7.

. Ministério da Educação e Cultura. Portaria n. ${ }^{\circ}$ 577, de 27 de abril de 2017. Diário

Oficial da União, 2017b. Disponível em: https://www.brasildefato.com.br/2017/05/08/ membros-do-forum-nacional-de-educacao-criticam-exclusao-de-membros-da-sociedadecivil/. Acesso em: 2 abr. 2017. 
Presidência da República. Decreto de 26 de abril de 2017, que convoca a 3. ${ }^{\text {a }}$ Conferência Nacional de Educação. 2017c. Disponível em: shttp://www.planalto.gov.br/ ccivil 03/ ato2015-2018/2017/dsn/Dsn14456.htm>. Acesso em:

Presidência da República. Decreto de 9 de maio de 2016, que convoca a $3^{a}$. Conferência Nacional de Educação. 2016b. Disponível em: <http://fne.mec.gov.br/ documentos/conae-2018>. Acesso em: 17 maio 2017.

CAMPANHA NACIONAL PELO DIREITO À EDUCAÇÃO. Tudo sobre a incidência da campanha na revisão periódica universal da ONU. 2017. Disponível em: <http:// campanha.org.br/direitos-humanos/tudo-sobre-a-incidencia-da-campanha-na-revisaoperiodica-universal-da-onu/>. Acesso em: 28 maio 2017.

FÓRUM NACIONAL DE EDUCAÇÃO. CONAE 2018: Conferência Nacional de Educação. Documento-Referência. Brasília: Fórum Nacional de Educação, 2017a. Disponível em: $\leq$ http://www.cedes.unicamp.br/politicas publicas/676>. Acesso em: 3 abr. 2017.

. Documento Referência da CONAE. Brasília, 2017b.

MINISTÉRIO PÚBLICO FEDERAL. PFDC pede ao MEC explicaçôes sobre realização da Conferência Nacional de Educação. 2017. Disponível em: <http://www.mpf.mp.br/pgr/ noticias-pgr/pfdc-pede-ao-mec-explicacoes-sobre-realizacao-da-conferencia-nacional-deeducacao $>$. Acesso em: 12 maio 2017.

PORTUGAL, A.; LOPES, C. Projeto de Decreto Legislativo n. ${ }^{\circ}$ 644, de 2017. Susta, nos termos do art. 49, V, da Constituição, a vigência da Portaria Normativa n. ${ }^{0}$ 577, de 27 de abril de 2017, que "Altera as Portarias MEC n. ${ }^{\circ}$ 1.407, de 14 de dezembro de 2010; Portaria MEC n. ${ }^{\circ}$ 502, de 9 de maio de 2012, e Portaria MEC n. ${ }^{\circ} 1.033$, de 9 de dezembro de 2014 que dispóem sobre a instituição do Fórum Nacional de Educação - FNE e sua composição". 2017a. Disponível em: shttp://www.camara.gov.br/proposicoesWeb/prop mostrarintegra? codteor $=1556315 \&$ filename $=\mathrm{PDC}+644 / 2017>$. Acesso em: 3 jun. 2017.

;___. Projeto de Decreto Legislativo n. ${ }^{\circ}$ 645, de 2017-CONAE. Susta, nos termos do art.49, V, da Constituição, a vigência do Decreto de 26 de abril de 2017, que convoca a

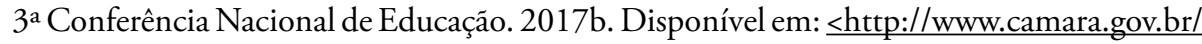
proposicoes Web/prop mostrarintegra? codteor $=1556314 \&$ filename $=\mathrm{PDC}+645 / 2017>$. Acesso em: 3 jun. 2017.

PROCURADORIA FEDERAL DOS DIREITOS DO CIDADÃO. MPF pede imediata revogação de portaria que altera composição do Fórum Nacional de Educação. 2017. Disponível em: shttp://midia.pgr.mpf.gov.br/pfdc/hotsites/informativo-pfdc/2017/ maio/110517.html $>$. Acesso em: 3 jun. 2017.

UCZAI, P. et al. Projeto de Decreto Legislativo n. ${ }^{\circ}$ 641/2017 - CONAE. Susta o Decreto de

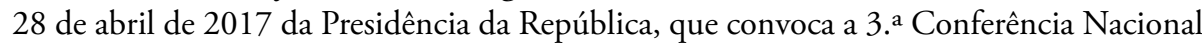
de Educação. 2017a. Disponível em: <http://www.camara.gov.br/proposicoesWeb/prop mostrarintegra? codteor $=1551839 \&$ filename $=\mathrm{PDC}+641 / 2017>$. Acesso em: 3 jun. 2017.

et al. Projeto de Decreto Legislativo n. ${ }^{\circ}$ 646/2017 - FNE. Susta a Portaria no 577, de 27 de abril de 2017, que "dissolve o Fórum Nacional de Educação". 2017b. Disponível em: <http://www.camara.gov.br/proposicoesWeb/prop mostrarintegra? codteor $=1551949$ \&filename $=$ PDC+646/2017 $>$. Acesso em: 3 jun. 2017. 